TITLE:

\title{
Application of neutron activation analysis to micro gram scale of solid samples
}

\section{$\operatorname{AUTHOR}(\mathrm{S})$ :}

Sekimoto, Shun; Shirai, Naoki; Ebihara, Mitsuru

\section{CITATION:}

Sekimoto, Shun ...[et al]. Application of neutron activation analysis to micro gram scale of solid samples. Journal of Radioanalytical and Nuclear Chemistry 2016, 307(3): 1757-1764

\section{ISSUE DATE:}

2016-03

URL:

http://hdl.handle.net/2433/217404

\section{RIGHT:}

(c) 2015 Akadémiai Kiadó, Budapest, Hungary; The final publication is available at Springer via

http://dx.doi.org/10.1007/s10967-015-4370-4; The full-text file will be made open to the public on 1 March 2017 in accordance with publisher's 'Terms and Conditions for Self-Archiving'.; この論文は出版社版でありません。引用の際に は出版社版をご確認ご利用ください。; This is not the published version. Please cite only the published version. 
Journal of Radioanalytical and Nuclear Chemistry

Special Issue (SI): MARC X

LOG NUMBER OF PAPER: 374

TITLE OF PAPER: Application of neutron activation analysis to micro gram scale of solid samples

AUTHORS: Shun Sekimoto ${ }^{\mathrm{a}, *},{ }^{*}$ Naoki Shirai ${ }^{\mathrm{b}}$ and Mitsuru Ebihara ${ }^{\mathrm{b}}$

POSTAL ADDRESS OF EACH AUTHOR:

a Research Reactor Institute, Kyoto University, 2-1010 Asashiro-nishi, Kumatori, Sen-nan, Osaka 590-0494, Japan

b Department of Chemistry, Tokyo Metropolitan University, 1-1 MinamiOsawa, Hachioji, Tokyo 192-0397, Japan

*CORRESPONDING AUTHOR'S

E-MAIL ADRESS: sekimoto@rri.kyoto-u.ac.jp

TELEPHONE NUMBER: +81-72-451-2480

FAX NUMBER: +81-72-451-2622 
Journal of Radioanalytical and Nuclear Chemistry

\section{Title page}

2 Names of the authors: Shun Sekimoto, Naoki Shirai, Mitsuru Ebihara

3 Title: Application of neutron activation analysis to micro gram scale of solid samples

4 Affiliation(s) and address(es) of the author(s):

5 Shun Sekimoto

6 at Research Reactor Institute, Kyoto University, 2-1010 Asashiro-nishi, Kumatori, Sen-

7 nan, Osaka 590-0494, Japan

$8 \quad$ Naoki Shirai and Mitsuru Ebihara

9 at Department of Chemistry, Tokyo Metropolitan University, 1-1 Minami-Osawa,

10 Hachioji, Tokyo 192-0397, Japan

11

12 E-mail address of the corresponding author: sekimoto@rri.kyoto-u.ac.jp

13 


\section{Introduction}

33 Neutron activation analysis (NAA) has been used in various research fields, such as geo-

34 and cosmochemistry, environmental science, biology, archeology, etc. Since instrumental

\section{gram scale of solid samples}

\author{
Shun Sekimoto ${ }^{1}$, Naoki Shirai ${ }^{2}$, and Mitsuru Ebihara ${ }^{2}$
}

${ }^{1}$ Research Reactor Institute, Kyoto University, 2-1010 Asashiro-nishi, Kumatori, Sen-nan, Osaka 590-0494, Japan

${ }^{2}$ Department of Chemistry, Tokyo Metropolitan University, 1-1 Minami-Osawa, Hachioji, Tokyo 192-0397, Japan

An instrumental neutron activation analysis (INAA) procedure for analyzing extremely small samples was developed and applied to two kinds of extraterrestrial samples. A few mg of the Allende meteorite as well as the JB-1 basalt can work well as a reference sample for a relative method. To evaluate the applicability of this INAA procedure, detection limits are presented and compared with the elemental contents in a potential sample to be analyzed. The possibility of reuse of neutron-irradiated samples for mass spectrometry was noted by indicating degree of increase in isotopic abundance for noble gas and long-lived radioactive nuclides.

\section{Keywords}

Neutron activation analysis, relative method, magnetic spherule, Kilabo chondrite 


\section{Journal of Radioanalytical and Nuclear Chemistry}

35 NAA (INAA) is a non-destructive and multi-elemental analysis method, it is suitable for

36 precious samples and, especially, for such specimens as those highly desired to be neither

37 physically decomposed nor chemically dissolved. Meteorites are the best example for

38 such samples. Chondritic meteorites (chondrites) and iron meteorites contain relatively

39 high contents of Co and Ir compared with those in the earth crust. As Co and Ir have high

40 sensitivity in NAA, they can be good markers for the identification of such

41 extraterrestrial materials [1, 2]. In NAA of chondrites, a few tens mg of specimen is

42 commonly used. For such a case, a few hundred $\mu \mathrm{gg}^{-1}$ of Ir and a few hundred mg kg-1

43 of Co can be reliably determined. When an extremely small size (e.g., micro gram) of

44 samples such as micrometeorites recovered on the Earth surface and tiny particles

45 returned from extraterrestrial asteroids are to be analyzed by INAA, the conventional

46 INAA procedure used for a few tens $\mathrm{mg}$ [3] is not suitable. For such tiny samples,

47 neutron irradiation with high neutron flux and long irradiation time (namely, high neutron

48 dose) is required. For the irradiation with high neutron dose, polyethylene bags for

49 holding samples are not usable because they are prone to radiation damage. Polyethylene

50 bags are also not suitable for holding tiny grain samples. It is, therefore, very important to

51 design an appropriate sample holder for irradiating small grain samples.

52 In this study, we aimed to develop the INAA procedure for analyzing a single grain of

53 down to micro and sub-micro grams in mass. At first, we present the INAA procedure

54 applicable to such samples. As we use a relative method for quantification, the

55 preparation of reference samples and the evaluation for their suitability are of concern

56 and, therefore, described in detail. Then, two typical examples for the application of the

57 proposed procedure are shown with limited scientific discussion. From those experiments,

58 the applicability of the procedure is described from several viewpoints including

59 detection limits and the degree of increase in isotopic abundance induced by neutron

60 irradiation.

\section{$61 \quad$ Experimental}

\section{Sample preparation for test samples}


Journal of Radioanalytical and Nuclear Chemistry

63 Two different types of small samples (a meteoritic grain and a magnetic spherule) were 64 targeted in this study. For the meteoritic grain sample, a chunk of the Kilabo (LL6)

65 chondrite was crushed and a single piece was picked. A magnetic spherule (6.5 $\mu \mathrm{g})$ was

66 separated from the Pacific Ocean sea sediment by a hand magnet. A quartz disc (9 mm

$67 \phi \times 1 \mathrm{~mm}$ thickness) with a small pit (1 $\mathrm{mm} \phi \times 0.3 \mathrm{~mm}$ depth) was used for neutron

68 irradiation of these small samples. Each sample was carefully placed into the pit. The

69 manner in which the spherule sample is placed into the pit in the quartz disc is shown in

70 Supplementary Information. Then, the disc was covered with a quartz disc (9 $\mathrm{mm} \phi$ x 1

71 mm thickness) and the sample holder assembly was wrapped tightly with high-purity

72 aluminum foil.

74 Sample preparation for reference samples

75 Two reference samples with different elemental compositions were used; the Allende

76 meteorite powder (1.66 mg) prepared by the Smithsonian Institution (USMN 3529; split

7722 and position 6) and the basaltic rock reference sample JB-1 prepared by Geological

78 Survey of Japan (1.12 mg). Each sample was sealed into a synthesized quartz tube (1 mm

79 inner $\phi$ and $2.7 \mathrm{~mm}$ outer $\phi \times 35 \mathrm{~mm}$ length), which was then wrapped with $\mathrm{Al}$ foil for the

80 safety.

81

82 Neutron irradiation

83 The Kilabo piece and the magnetic spherule, together with the two reference monitor

84 samples, were placed in an aluminum irradiation capsule (10 mm $\phi$ x $75 \mathrm{~mm}$ length). The

85 neutron irradiation was performed for 45 hours at the hydro-irradiation port of Kyoto

86 University Reactor (KUR) in Kyoto University Research Reactor Institute (KURRI)

87 under $1 \mathrm{MW}$ operation, where thermal and fast neutron fluxes are $1.6 \times 10^{13} \mathrm{n} \mathrm{cm}^{-2} \mathrm{~s}^{-1}$ and

$887.8 \times 10^{12} \mathrm{n} \mathrm{cm}^{-2} \mathrm{~s}^{-1}$, respectively.

89

90 Gamma-ray spectrometry for test and reference samples

91 Gamma rays emitted from irradiated samples were measured using Ge semiconductor

92 detectors at KURRI. After irradiation, test samples were transferred into new (non-

93 irradiated) quartz holders of the same size as used for irradiation and subjected to 


\section{Journal of Radioanalytical and Nuclear Chemistry}

94 gamma-ray counting. Measurements were repeated with different cooling intervals and 95 total of 10 and seven elements were determined for a meteorite piece and a magnetic 96 spherule, respectively. Among the ten elements determined for the piece of the Kilabo 97 meteorite, $\mathrm{Na}, \mathrm{La}, \mathrm{Sm}$ and Au were determined with measurement time of 110,00098 120,000 sec after a few days cooling. The rest of elements (Sc, Cr, Fe, Co, Ni and Zn) 99 were determined with measurement time of 110,000-140,000 sec after two weeks cooling.

100 For the magnetic spherule, Na, Cr, Fe, Co, Ni, Ir and Au were determined. Gamma-ray 101 counting for the spherule was done within a day for Na-determination and within a week 102 for the rest. Gamma-ray spectrometry for reference samples was completed in the same 103 manner as described in Ebihara et al. [4].

106 In relative method of INAA [3], test samples and reference samples are usually 107 prepared in the same shape and measured at the same position in gamma-ray counting for 108 simplifying the data reduction procedure and reducing analytical uncertainty. In this study, 109 however, both sample shape and counting position were largely different between the test 110 samples and the reference samples. Because the sample size was different by three orders

111 of magnitude in mass and, hence, the induced radioactivity was similarly different, the 112 counting position was changed to keep the counting loss smaller than $10 \%$. The piece of

113 Kilabo and the magnetic spherule were measured as closely as possible to the Ge detector 114 surface while the reference samples were placed at $8 \mathrm{~cm}$ apart from the detector surface. 115 Although the reference samples were sealed into quartz tubes, they could be regarded as 116 point sources just like the tiny test samples when they were place at such position. The 117 difference in counting efficiency between the two positions was corrected by using 118 commercially available checking sources of radioactivity. Data reduction

121 Nuclear data related to this study are summarized in Supplementary Information. An (n, $\gamma)$ 122 reaction was used in NAA for all elements except $\mathrm{Ni}$, for which an (n,p) reaction was 123 used. The elemental contents were determined by a relative method. Some elements (Sc, 
Journal of Radioanalytical and Nuclear Chemistry

$124 \mathrm{Cr}, \mathrm{Fe}, \mathrm{Co}, \mathrm{Ni}$ and $\mathrm{Sm}$ ) were determined by using both reference monitors and two sets of

125 results were consistent. Allende was used for the determination of $\mathrm{Na}$, Ir and Au while $\mathrm{Zn}$

126 and La were determined by JB-1. Only upper limits were calculated for Ir in the piece of

127 Kilabo and for Sc, Zn, La and Sm in the magnetic spherule. The definition of an upper

128 limit has been reported elsewhere [4]. Certified values for Allende and JB-1 given by

129 Jarosewich et al. [5] and by Imai et al. [6], respectively, were used for reference values.

\section{$130 \quad$ Results and discussion}

\section{Consistencies in reference monitor samples}

132 For quantification in INAA, two reference samples (the Allende meteorite and the JB-1

133 basalt) having different elemental contents were used. We have conducted similar INAA

134 experiments where tiny grain samples collected by the spacecraft were analyzed by using

135 Allende and JB-1 as reference samples. Hereafter, these experimental runs named run-2

136 [4] and run-3 [7] are discussed in comparison with the present study, which is named run-

137 1. Table 1 summarizes experimental conditions of these three runs. It is meaningful to

138 compare the activity of radioactive nuclides used in INAA for two different reference

139 samples. Figure 1 compares the gamma rays counting rate per unit mass for each target

140 element, hereafter gamma-ray intensity, among three runs. In runs 2 and 3, iron reagents

141 (iron oxide $\left(\mathrm{Fe}_{2} \mathrm{O}_{3}\right)$ powder or iron metal ( $\mathrm{Fe}$ ) powder) were used in addition to Allende

142 and JB-1 as reference samples and their data are shown. The gamma rays counting rate is

143 gamma ray counts per second and correspond to gamma ray energies designated for

144 individual nuclides shown in Fig. 1.

146 Table 1 Experimental conditions in run-1, run-2 and run-3 $3^{\text {a }}$ 
Journal of Radioanalytical and Nuclear Chemistry

\begin{tabular}{|c|c|c|c|}
\hline & $\begin{array}{c}\text { Run-1 } \\
\text { (This work) }\end{array}$ & Run-2 $2^{b}$ & Run- $3^{c}$ \\
\hline Irradiation time (h) & 45 & 28 & 19 \\
\hline Thermal neutron flux $\left(\mathrm{n} \mathrm{cm}^{-2} \mathrm{~s}^{-1}\right)$ & $1.6 \times 10^{13}$ & $8.2 \times 10^{13}$ & $8.2 \times 10^{13}$ \\
\hline Fast neutron flux (n $\mathrm{cm}^{-2} \mathrm{~s}^{-1}$ ) & $7.8 \times 10^{12}$ & $3.9 \times 10^{13}$ & $3.9 \times 10^{13}$ \\
\hline Operation power (MW) & 1 & 5 & 5 \\
\hline \multicolumn{4}{|l|}{ Mass of reference monitors } \\
\hline Allende (mg) & 1.66 & 2.00 & 1.67 \\
\hline JB-1 (mg) & 1.12 & 1.62 & 1.03 \\
\hline Iron oxide $\left(\mathrm{Fe}_{2} \mathrm{O}_{3}\right)$ powder $(\mathrm{mg})$ & - & $2.23^{\mathrm{d}}$ & - \\
\hline Iron metal (Fe) powder (mg) & - & - & 3.17 \\
\hline
\end{tabular}

150 The nine nuclides shown in Fig. 1 were determined both for Allende and JB-1. Relative 151 gamma-ray intensities of ${ }^{24} \mathrm{Na},{ }^{46} \mathrm{Sc}$ and ${ }^{59} \mathrm{Fe}$ in both reference samples are highly 152 consistent for the three runs. Such a consistency can also be seen for Fe reagents. Kong 153 and Ebihara [8] evaluated the consistency in elemental contents in the mg size of JB-1 154 and confirmed that JB-1 is well homogenized for its use in mg. Figure 1 further confirms 155 that Allende can also be used as a reference sample for mg scale of sample at least for $\mathrm{Na}$, 156 Sc and Fe. For the rest of elements, Allende and JB-1 show a small inconsistency, most of 157 which may be due to poor counting statistics for either sample. For example, Allende 158 tends to have relatively low contents of rare earth elements (La and Sm), whereas JB-1 159 has a low content of $\mathrm{Ni}$ and Zn. Depending upon elemental contents, either Allende or 160 JB-1 may be used for a reference sample.

161 There appears an apparent inconsistency in Cr data between the two reference samples, 162 with JB-1 having systematically higher gamma-ray intensity. This is undoubtedly due to 163 an erroneous reference value (425 mg $\mathrm{kg}^{-1}$ ) of Cr for JB-1. If a proposed value (475 mg $164 \mathrm{~kg}^{-1}$ ) [8] is instead used, an excellent consistency can be seen as shown in Fig. 1 for ${ }^{51} \mathrm{Cr}$. 
Journal of Radioanalytical and Nuclear Chemistry
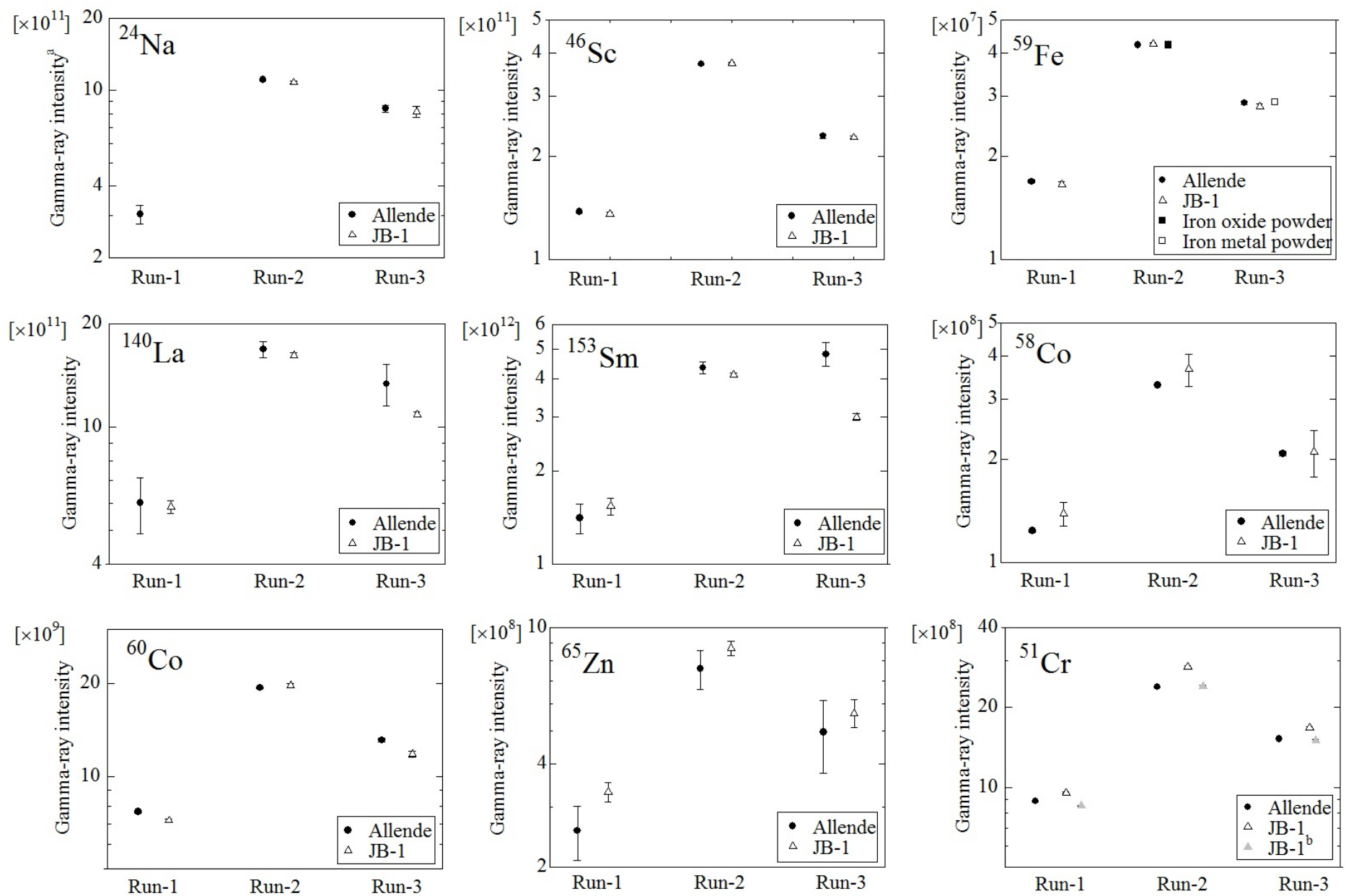

Fig. 1 Gamma-ray intensities of ${ }^{24} \mathrm{Na},{ }^{46} \mathrm{Sc},{ }^{59} \mathrm{Fe},{ }^{140} \mathrm{La},{ }^{153} \mathrm{Sm},{ }^{58} \mathrm{Co},{ }^{60} \mathrm{Co},{ }^{65} \mathrm{Zn}$ and ${ }^{51} \mathrm{Cr}$ in reference monitors

167 for run-1, run-2 and run-3 a Gamma-ray intensity means the gamma rays counting rate per unit mass for each target elements. ${ }^{\mathrm{P}}$ Proposed value 168 for $\mathrm{Cr}$ in $\mathrm{JB}-1$ is $475 \mathrm{mg} \mathrm{kg}^{-1}$ [8]. 
Journal of Radioanalytical and Nuclear Chemistry

\section{Elemental abundances for Kilabo and magnetic spherule samples}

Instrumental NAA results of the Kilabo piece and the magnetic spherule are summarized in Table 2. As for the spherule sample, elemental concentrations are also given. The magnetic spherule analyzed is characterized by high concentrations of iron (601 g kg-1) and nickel (50 $\mathrm{g} \mathrm{kg}^{-1}$ ). These two elements comprise $65 \%$ of the bulk mass. Its Ir concentration (2.51 mg kg-1) also is extremely high compared with terrestrial samples. Apparently, this spherule is extraterrestrial in origin. Such spherules are called cosmic spherules and often picked up from the deep sea sediment [9]. Elemental abundances of this spherule are illustrated in Fig. 2, where abundances are normalized to CI chondrite values [10]. Data for the other magnetic spherules from our previous work [11] are also indicated for comparison. Based on the elemental composition, magnetic spherules can be classified into two groups: one group have high CI-normalized abundances of Ir, Co, Ni and Fe (siderophile elements), and low abundances of Cr and Sc (lithophile elements), whereas another group have unfractionated CI-normalized abundances of both siderophile and lithophile elements. The magnetic spherule analyzed in this study apparently belongs to the former group. There has not been reported for Sc values for this group. It now becomes obvious that Sc is even lower than $\mathrm{Cr}$ in their CI-normalized abundances.

Table 2 Elemental contents in Kilabo and magnetic spherule analyzed by INAA in this study

\begin{tabular}{|c|c|c|c|}
\hline & Kilabo & \multicolumn{2}{|c|}{$\begin{array}{c}\text { Spherule } \\
\text { Content }\end{array}$} \\
\hline $\mathrm{Sm}$ & $0.38 \pm 0.04 \mathrm{pg}$ & $<0.4 \mathrm{pg}$ & $<0.06 \mathrm{mg} \mathrm{kg}^{-1}$ \\
\hline $\mathrm{La}$ & $2.6 \pm 0.3 \mathrm{pg}$ & $<1.6 \mathrm{pg}$ & $<0.24 \mathrm{mg} \mathrm{kg}^{-1}$ \\
\hline $\mathrm{Sc}$ & $22.2 \pm 0.4 \mathrm{pg}$ & $<1.8 \mathrm{pg}$ & $<0.27 \mathrm{mg} \mathrm{kg}^{-1}$ \\
\hline $\mathrm{Fe}$ & $0.576 \pm 0.007 \mu \mathrm{g}$ & $3.90 \pm 0.05 \mu \mathrm{g}$ & $601 \pm 8 \mathrm{~g} \mathrm{~kg}^{-1}$ \\
\hline $\mathrm{Na}$ & $7.93 \pm 0.12 \mathrm{ng}$ & $0.406 \pm 0.008 \mathrm{ng}$ & $62.5 \pm 1.3 \mathrm{mg} \mathrm{kg}^{-1}$ \\
\hline $\mathrm{Co}$ & $0.589 \pm 0.008 \mathrm{ng}$ & $20.4 \pm 0.2 \mathrm{ng}$ & $3140 \pm 40 \mathrm{mg} \mathrm{kg}^{-1}$ \\
\hline $\mathrm{Cr}$ & $4.60 \pm 0.04 \mathrm{ng}$ & $1.06 \pm 0.06 \mathrm{ng}$ & $164 \pm 9 \mathrm{mg} \mathrm{kg}^{-1}$ \\
\hline $\mathrm{Ni}$ & $14.5 \pm 0.3 \mathrm{ng}$ & $328 \pm 4 \mathrm{ng}$ & $50 \pm 1 \mathrm{~g} \mathrm{~kg}^{-1}$ \\
\hline $\mathrm{Au}$ & $0.62 \pm 0.03 \mathrm{pg}$ & $0.59 \pm 0.05 \mathrm{pg}$ & $0.091 \pm 0.007 \mathrm{mg} \mathrm{kg}^{-1}$ \\
\hline $\mathrm{Zn}$ & $1.4 \pm 0.1 \mathrm{ng}$ & $<0.98 \mathrm{ng}$ & $<0.1 \mathrm{~g} \mathrm{~kg}^{-1}$ \\
\hline $\mathrm{Ir}$ & $<0.068 \mathrm{pg}$ & $16.3 \pm 0.4 \mathrm{pg}$ & $2.51 \pm 0.06 \mathrm{mg} \mathrm{kg}^{-1}$ \\
\hline
\end{tabular}


Journal of Radioanalytical and Nuclear Chemistry

190

191

192

193

194

195

196

197

198

199

200

201

202

203

204

205

206

The Kilabo sample analyzed in this study is a small silicate piece. Therefore, its chemical composition cannot be the same as that of the bulk Kilabo meteorite. As no mineralogical and petrological information is available for the Kilabo piece sample, the detailed cosmochemical discussion cannot be developed. Here, only Ni and Co contents are concerned. Cobalt and $\mathrm{Ni}$ are known to behave similarly cosmochemically [12] as well as geochemically. Both elements tend to be hosted in metals in ordinary chondrites like Kilabo. Figure 3 shows the relationship between $\mathrm{Co} / \mathrm{Fe}$ and $\mathrm{Ni} / \mathrm{Fe}$ ratios for the Kilabo piece. In addition, data for CI chondrite [10], LL6 chondrite (bulk) [13] and metal separate of LL6 and L6 chondrites [14] are also shown for comparison. The solid line represents the $\mathrm{Co} / \mathrm{Ni}$ ratio of $\mathrm{CI}$ chondrite, on which the Kilabo piece sample is placed along with LL6 bulk and metal samples. This suggests that the Kilabo piece contains a tiny metal grain inside. A similar chemical characteristic was observed in tiny silicate grains recovered from the asteroid Itokawa by the Hayabusa spacecraft [7]. Their Co/Fe and $\mathrm{Ni} / \mathrm{Fe}$ ratios are similar to those of the Kilabo piece, falling on the CI line as seen in Fig. 3.

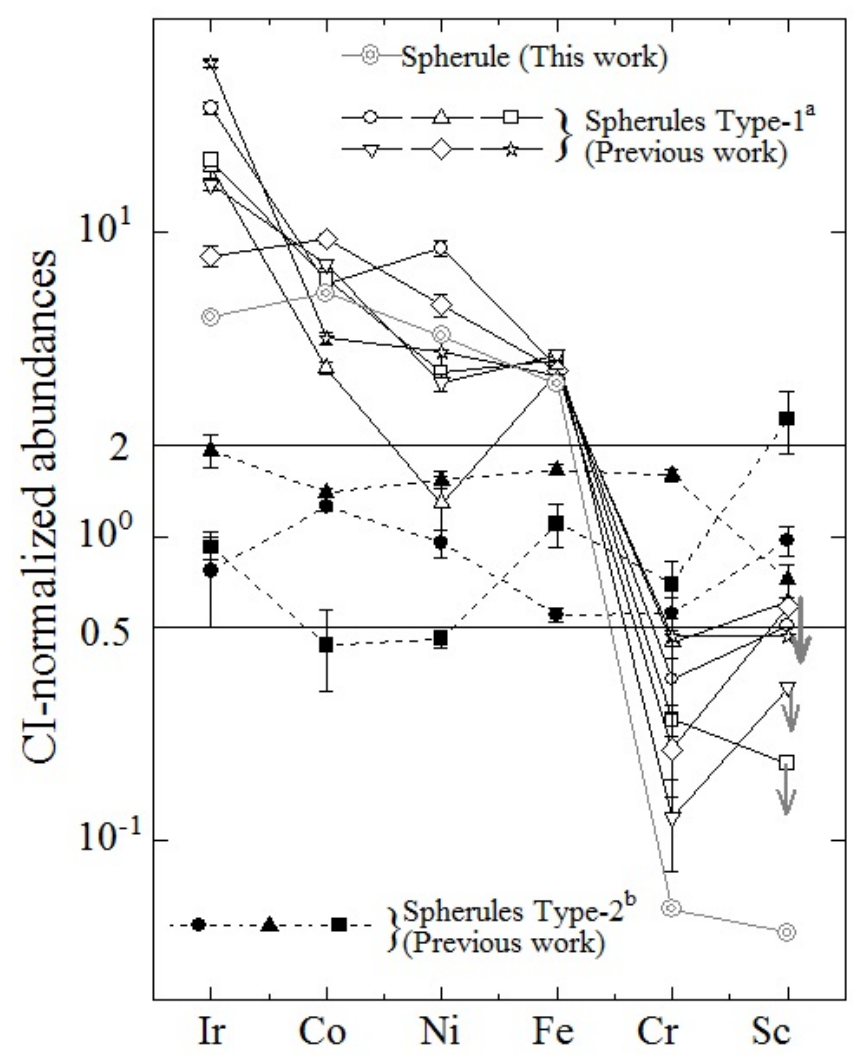

Fig. 2 CI-normalized abundances of Ir, Co, Ni, Fe, Cr and Sc in cosmic spherules 
Journal of Radioanalytical and Nuclear Chemistry

${ }^{a}$ Open symbols indicate spherules which have high CI-normalized abundances of Ir, Co, Ni and siderophile and lithophile elements.

211 As the $\mathrm{Co} / \mathrm{Ni}$ ratio in the Kilabo piece is chondritic, the kilabo piece might contain 0.5$2120.6 \mathrm{pg}$ of Ir if we assume that the $\mathrm{Ir} / \mathrm{Co}$ and $\mathrm{Ir} / \mathrm{Ni}$ ratios in the Kilabo piece are equal to 213 those in CI chondrite [10]. Although only an upper limit was derived for the Kilabo piece, 214 it is clear that Ir is depleted in the tiny metal grain that the Kilabo piece contains. From 215 the view point of Ir-depletion, Kilabo and Itokawa grains thus appear alike.

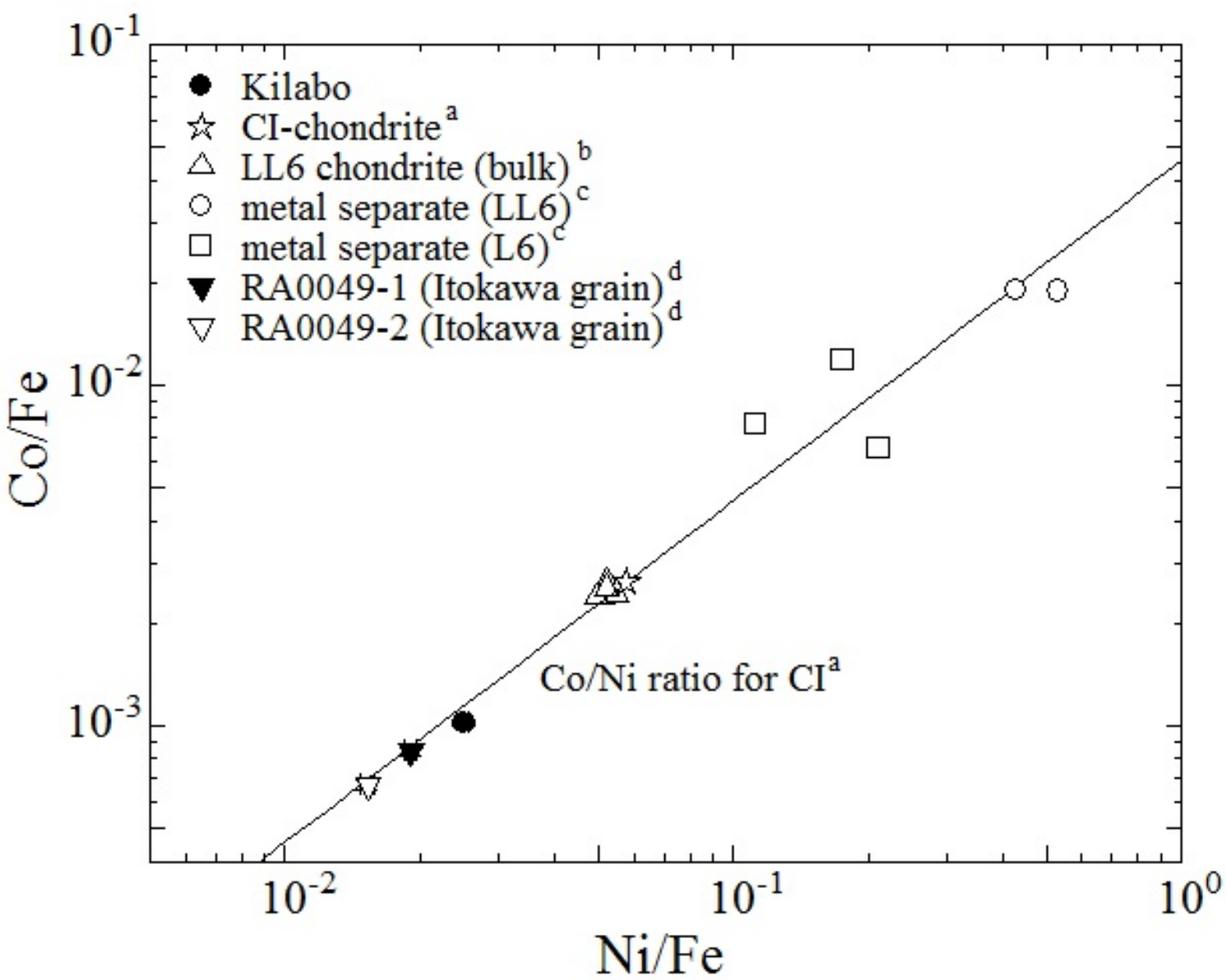

Fig. 3 Correlation between $\mathrm{Co} / \mathrm{Fe}$ and $\mathrm{Ni} / \mathrm{Fe}$ ratios in several astromaterials 
Journal of Radioanalytical and Nuclear Chemistry

221 Detection limits of the 11 elements measured in this study are estimated under the present

222 experimental condition. A detection limit is defined as a value corresponding to three

223 sigma of background counts at the peak area of the gamma-ray emitted by a nuclide of

224 interest. Calculated values are listed in Table 3, in which data for the previous

225 experimental runs (run-2 and/or run-3) also are shown for comparison. Detection limit

226 values were obtained based on data on either or both of the samples analyzed in

227 individual runs. The detection limit values for run-1 (this study) are higher than those for

228 runs-2/3 by factors of 2 to 20. Detection limits are dependent on experimental conditions

229 such as the sample size, irradiation time, neutron flux, gamma-ray counting time and

230 counting efficiency. In INAA, the detection limit is also largely controlled by the co-

231 existing elements in the matrix. Therefore, detection limit values are to be regarded as

232 information values but the values in Table 3 must be informative in the analysis of similar

233 samples to those analyzed in this study, for example, micro meteorites, meteorite pieces

234 and cosmic spherules.

235 Table 3 Detection limits for individual elements

\begin{tabular}{|c|c|c|c|c|}
\hline & \multicolumn{2}{|c|}{ Detection limit (pg) } & \multirow{2}{*}{$\begin{array}{l}\text { Concentration range } \\
\text { in Chondrite }^{\mathrm{c}}\end{array}$} & \multirow{2}{*}{$\begin{array}{c}\text { Content range in } \\
\text { Chondrite of } 0.05 \\
\text { micro-g (pg) }\end{array}$} \\
\hline & $\begin{array}{c}\text { This work }^{\mathrm{a}} \\
45 \text { h irradiation }^{(1 \mathrm{MW})}\end{array}$ & $\begin{array}{c}\text { Previous work } \\
28 \text { h irradiation } \\
(5 \mathrm{MW})\end{array}$ & & \\
\hline $\mathrm{Na}$ & 20 & 1 & $1800-6900 \mathrm{mg} \mathrm{kg}^{-1}$ & $90-345$ \\
\hline Sc & 0.4 & 0.03 & $6-11 \mathrm{mg} \mathrm{kg}^{-1}$ & $0.30-0.55$ \\
\hline $\mathrm{Cr}$ & 40 & 4 & $2650-4160 \mathrm{mg} \mathrm{kg}^{-1}$ & $133-208$ \\
\hline $\mathrm{Fe}$ & 2800 & 270 & $18-38 \%$ & $9100-19000$ \\
\hline Co & 3 & 0.4 & $480-1100 \mathrm{mg} \mathrm{kg}^{-1}$ & $24-55$ \\
\hline $\mathrm{Ni}$ & 340 & $110^{\mathrm{e}, \mathrm{f}}$ & $1.1-2.6 \%$ & $550-1285$ \\
\hline $\mathrm{Zn}$ & 150 & 12 & $18-315 \mathrm{mg} \mathrm{kg}^{-1}$ & $0.9-15.8$ \\
\hline $\mathrm{La}$ & 0.5 & 0.1 & $235-585 \mu g \mathrm{~kg}^{-1}$ & $0.012-0.029$ \\
\hline $\mathrm{Sm}$ & 0.1 & 0.02 & $140-294 \mu g \mathrm{~kg}^{-1}$ & $0.007-0.015$ \\
\hline $\mathrm{Ir}$ & $0.3^{\mathrm{d}}$ & $0.02^{\mathrm{e}, \mathrm{f}}$ & $380-1070 \mu \mathrm{g} \mathrm{kg}^{-1}$ & $0.019-0.054$ \\
\hline $\mathrm{Au}$ & 0.02 & 0.01 & $120-330 \mu \mathrm{g} \mathrm{kg}$ & $0.006-0.017$ \\
\hline
\end{tabular}

$236{ }^{\mathrm{a}}$ Calculated for the piece of Kilabo, unless otherwise noted. ${ }^{\mathrm{b}}$ Calculated for Itokawa particle

237 (0.017-0.048 $\mu \mathrm{g})$, unless otherwise noted. ${ }^{\mathrm{C}}$ Data from [15]. ${ }^{\mathrm{d}}$ Calculated for spherule (6.5 $\left.\mu \mathrm{g}\right)$.

$238{ }^{\mathrm{e}}$ Calculated for Itokawa particle $(1.66 \mu \mathrm{g}) .{ }^{\mathrm{f}}$ Obtained by run-3 (19 h irradiation under 5MW

239 operation). 
Journal of Radioanalytical and Nuclear Chemistry

To evaluate the applicability of the INAA procedure described in this study, the

242 deduced detection limits are compared with the estimated elemental contents in $0.05 \mu \mathrm{g}$

243 of chondritic meteorites [15] in Table 3. It is obvious that Na, Cr, Fe, Co and Ni can be

244 easily determined for $0.05 \mu \mathrm{g}$ of chondrite by INAA with $45 \mathrm{~h}$ irradiation under $1 \mathrm{MW}$

245 operation (this work), while INAA with more than 28 h irradiation under 5MW operation

246 is required to determine Sc, Zn, Ir and Au. Even with the highest neutron doze (53 h

247 irradiation under 5 MW operation) available at KUR, La and Sm may not be determined

248 for such a small sample.

250 Degree of increase in isotopic abundance induced by neutron irradiation

251 As INAA is a nondestructive method of elemental analysis, the same sample once 252 subjected to INAA can be reused for different analytical purposes. For such a case, effects 253 caused by neutron irradiation are of concern. Major concerns are the induced 254 radioactivity and the increase in isotopic abundance including the production of long255 lived radioactive nuclides. Scientifically, the latter case is important by far and, therefore,

256 is considered here. In order to make the evaluation of degree of the increase in isotopic 257 abundance meaningful, used are the data from the experiment at run-3 [7], where $1.66 \mu \mathrm{g}$ 258 of a tiny grain from the asteroid Itokawa was irradiated by neutrons under the condition 259 listed in Table 1. Assuming the elemental composition of bulk LL chondrite [15] for this 260 grain, the number of produced nuclides with neutron irradiation was calculated based on 261 the Monte-Calro simulation code (MVP 2.0) [16] and the reaction cross section data 262 (JENDL-4.0) [17]. Both stable and unstable (radioactive) nuclides could be produced and 263 the result is summarized in Table 4. In calculation, the position of control rod, 264 temperature of the reactor core, and the combustion rate of nuclear fuel were all taken 265 into consideration, because the neutron irradiation of run-3 was performed near the 266 reactor core and, therefore, these factors affect the neutron energy spectrum. The 267 produced nuclides in Table 4 are grouped into stable nuclides $\left({ }^{21} \mathrm{Ne},{ }^{22} \mathrm{Ne}\right.$ and $\left.{ }^{38} \mathrm{Ar}\right)$ and 268 long-lived radioactive nuclides $\left({ }^{36} \mathrm{Cl},{ }^{26} \mathrm{Al}\right.$ and $\left.{ }^{10} \mathrm{Be}\right)$. These nuclides are typical 269 cosmogenic nuclides and radionuclides produced by nuclear reactions triggered by 270 cosmic rays and commonly detected in extraterrestrial materials like meteorites. 
Journal of Radioanalytical and Nuclear Chemistry

271 Table 4 Production of some cosmogenic nuclides from $1.66 \mu$ g of LL chondrite by

272 neutron-induced reaction in INAA ${ }^{\mathrm{a}}$

\begin{tabular}{|c|c|c|c|c|}
\hline $\begin{array}{c}\text { Target } \\
\text { nuclides }\end{array}$ & Reaction & $\begin{array}{c}\text { Produced } \\
\text { nuclides }\end{array}$ & $\begin{array}{c}\text { Number of } \\
\text { Produced nuclides }\end{array}$ & $\begin{array}{c}\text { Number of nuclides } \\
\text { (original) }\end{array}$ \\
\hline \multicolumn{5}{|c|}{ Stable nuclides (noble gas)-production } \\
\hline${ }^{24} \mathrm{Mg}$ & $(\mathrm{n}, \alpha)$ & ${ }^{21} \mathrm{Ne}$ & $1.58 \times 10^{8}$ & $1.15 \times 10^{7}$ \\
\hline${ }^{25} \mathrm{Mg}$ & $(\mathrm{n}, \alpha)$ & ${ }^{22} \mathrm{Ne}$ & $5.21 \times 10^{7}$ & $3.49 \times 10^{8}$ \\
\hline${ }^{37} \mathrm{Cl}$ & $(\mathrm{n}, \gamma), \beta^{-}$ & ${ }^{38} \mathrm{Ar}$ & $7.97 \times 10^{6}$ & $1.78 \times 10^{7}$ \\
\hline \multicolumn{5}{|c|}{ Radioactive nuclides-production } \\
\hline${ }^{35} \mathrm{Cl}$ & $(\mathrm{n}, \gamma)$ & ${ }^{36} \mathrm{Cl}$ & $2.53 \times 10^{9}$ & $9.06 \times 10^{2}$ \\
\hline${ }^{39} \mathrm{~K}$ & $(\mathrm{n}, \alpha)$ & ${ }^{36} \mathrm{Cl}$ & $3.24 \times 10^{7}$ & $9.06 \times 10^{2}$ \\
\hline${ }^{27} \mathrm{Al}$ & $(\mathrm{n}, 2 \mathrm{n})$ & ${ }^{26} \mathrm{Al}$ & $1.30 \times 10^{5}$ & $3.73 \times 10^{3}$ \\
\hline${ }^{13} \mathrm{C}$ & $(\mathrm{n}, \alpha)$ & ${ }^{10} \mathrm{Be}$ & $3.03 \times 10^{4}$ & $2.07 \times 10^{3}$ \\
\hline
\end{tabular}

${ }^{\mathrm{a}}$ Under the condition of run-3 in Table 2.

274 In Table 4, the calculated values are compared with numbers of corresponding nuclides 275 observed in extraterrestrial samples. For stable nuclides (of noble gases), measured values 276 for a different Itokawa grain are given for comparison [18]. It is well acknowledged that 277 noble gases are extremely sensitive in mass spectrometry. As seen in Table 4, calculated 278 values and measured values in the Itokawa grain are mostly comparable for all three 279 nuclides. For long-lived radionuclides, concentrations in the Gold Basin L4 chondrite (a 280 shower sample, UA-1188) [19] are given for comparison in Table 4. These data were 281 obtained by accelerator mass spectrometry. The measured values are smaller or much 282 smaller than the calculated values, with the difference varying by an order to six orders of 283 magnitude. Evidently the reuse of neutron-irradiated samples should not be allowed for 284 noble gas mass spectrometry and accelerator mass spectrometry for the study on noble 285 gas nuclides and long-lived radioactive nuclides, respectively.

\section{Conclusions}

287 In considering the cosmochemical importance of small grain samples, we developed the 288 INAA procedure for analyzing micro gram scale of solid samples. For quantification in 289 this INAA procedure a relative method using the Allende meteorite and the JB-1 basalt 290 was used. From a detailed comparison in the gamma-ray intensity for individual nuclides 
Journal of Radioanalytical and Nuclear Chemistry

291 between Allende and JB-1, it was confirmed that a few mg of Allende and JB-1 can be

292 used as reference monitors for a relative method and that Cr data in JB-1 should be the 293 proposed value of $475 \mathrm{mg} \mathrm{kg}^{-1}$.

294 Using this INAA procedure, elemental abundances for the Kilabo grain as meteoritic 295 sample and a magnetic spherule were obtained. This spherule sample was judged to be 296 extraterrestrial in origin from its Ir concentration and seemed to be similar to the other 297 spherules analyzed previously which have high CI-normalized abundances of siderophile 298 elements and low abundances of lithophile elements. The Kilabo grain appeared to be 299 similar to the silicate grain recovered from the asteroid Itokawa by the Hayabusa 300 spacecraft based on its Co and Ni contents.

301 To evaluate the applicability of this INAA procedure, detection limit values were 302 deduced. In $0.05 \mu \mathrm{g}$ of chondrite sample, $\mathrm{Na}, \mathrm{Cr}, \mathrm{Fe}, \mathrm{Co}$ and $\mathrm{Ni}$ can be easily determined 303 by this INAA procedure with $45 \mathrm{~h}$ irradiation under $1 \mathrm{MW}$ operation, while INAA with 304 more than $28 \mathrm{~h}$ irradiation under 5MW operation is required to determine Sc, $\mathrm{Zn}$, Ir and $305 \mathrm{Au}$. From evaluating degree of the increase in isotopic abundance induced by neutron 306 irradiation, evidently the reuse of neutron-irradiated samples should not be allowed for 307 noble gas mass spectrometry and accelerator mass spectrometry for the study on noble 308 gas nuclides $\left({ }^{21} \mathrm{Ne},{ }^{22} \mathrm{Ne}\right.$ and $\left.{ }^{38} \mathrm{Ar}\right)$ and long-lived radioactive nuclides $\left({ }^{36} \mathrm{Cl},{ }^{26} \mathrm{Al}\right.$ and $\left.309{ }^{10} \mathrm{Be}\right)$, respectively.

\section{$310 \quad$ Acknowledgements}

311 We thank Dr. T. Sano (Kyoto University Research Reactor Institute, KURRI) for 312 calculation of the number of stable and radioactive nuclides produced by neutron 313 irradiation. We are grateful to Prof. T. Ohtsuki (KURRI) for his help in the method for 314 neutron irradiation of small samples. The authors express their gratitude to the members 315 of the research reactor group in KURRI for the preparation and operation in the neutron 316 irradiation. This study was supported by Kyoto University Global COE Program 317 "International Center for Integrated Research and Advanced Education in Material 
Journal of Radioanalytical and Nuclear Chemistry

318 Science” (to SS). This study was supported by a grant-in-aid from the Ministry of

319 Education, Science and Culture (KAKENHI 25790081) in Japan for SS.

\section{References}

321

1. Ganapathy R, Brownlee DE, Hodge PW (1978) Silicate spherules from deep-sea sediments: confirmation of extraterrestrial origin. Science 201:1119-1121

2. Sekimoto S, Kobayashi T, Takamiya K, Ebihara M, Shibata S (2007) Instrumental neutron activation analysis of spherule samples recovered from the Pacific ocean sea sediment and Antarctic ice sheet. J Radioanal Nucl Chem. 272:447-450

3. Kong P, Ebihara M, Nakahara H (1996) Determination of 18 siderophile elements including all platinum group elements in chondritic metals and iron meteorites by instrumental neutron activation. Anal Chem. 68:4130-4134

4. Ebihara M, Shirai N, Sekimoto S, Nakamura T, Tsuchiyama A, Matsuno J, Matsumoto T, Abe M, Fujimura A, Ishibashi Y, Karouji Y, Mukai T, Okada T, Uesugi M, Yada T (2015) Chemical and mineralogical compositions of two grains recovered from asteroid Itokawa. Meteorit Planet Sci. 50:243-254

5. Jarosewich E, Clarke RS Jr., Barrows JN (1987) The Allende Meteorite reference sample. Smithson Contrib Earth Sci. 27:1- 12

6. Imai N, Terashima S, Itoh S, Ando A (1995) 1994 Compilation values for GSJ reference samples, igneous rock series. Geochem J. 29: 91-95

7. Ebihara M, Sekimoto S, Shirai N, Hamajima Y, Yamamoto M, Kumagai K, Oura Y, Ireland TR, Kitajima F, Nagao K, Nakamura T, Naraoka H, Noguchi T, Okazaki R, Tsuchiyama A, Uesugi M, Yurimoto H, Zolensky ME, Abe M, Fujimura A, Mukai T, Yada T (2011) Neutron activation analysis of a particle returned from asteroid Itokawa. Science 333:1119-1121.

8. Kong P, Ebihara M (1997) Reproducibility of elemental concentrations for JB-1, a GSJ rock reference sample, with special reference to Mo, W and Ta. Geochem J. 31: 339-344.

9. Murray J, Renard AF (1891) Report on Deep-Sea Deposits based on the specimens collected during the voyage of H.M.S. Challenger in the years 1872 to 1876, Neill 
Journal of Radioanalytical and Nuclear Chemistry

and Company, Edinburgh

10. Anders E, Grevesse N (1989) Abundances of the elements: Meteoritic and solar. Geochim Cosmochim Acta. 53:197-214

11. Sekimoto S, Kobayashi T, Takamiya K, Ebihara M, Shibata S (2008) Chemical composition of magnetic spherules collected from deep sea sediment. J Radioanal Nucl Chem. 278: 319-322

12. Wasson JT (1985) Meteorites-Their Record of Early Solar-System History, W. H Freeman and Company, New York

13. Kallemeyn GW, Rubin AE, Wang D, Wasson JT (1989) Ordinary chondrites: Bulk compositions, classification, lithophile-element fractionations and compositionpetrographic type relationships. Geochim Cosmochim Acta. 53: 2747-2767

14. Kong P, Ebihara M (1997) The origin and nebular history of the metal phase of ordinary chondrites. Geochim Cosmochim Acta. 61:2317-2329

15. Wasson JT, Kallemeyn GW (1988) Compositions of chondrites. Phil Trans R Soc A. 325:535-544

16. Nagaya Y, Okumura K, Mori T, Nakagawa M (2005) MVP/GMVP II: General purpose Monte Carlo codes for neutron and photon transport calculations based on continuous energy and multigroup methods. JAERI Rep. 1348:1-388

17. Shibata K, Iwamoto O, Nakagawa T, Iwamoto N, Ichihara A, Kunieda S, Chiba S, Furutaka K, Otuka N, Ohsawa T, Murata T, Matsunobu H, Zukeran A, Kamada S, Katakura J (2011) JENDL-4.0: A new library for nuclear science and engineering. J Nucl Sci Technol. 48:1-30

18. Nagao K, Okazaki R, Nakamura T, Miura YN, Osawa T, Bajo K, Matsuda S, Ebihara M, Ireland TR, Kitajima F, Naraoka H, Noguchi T, Tsuchiyama A, Yurimoto H, Zolensky ME, Uesugi M, Shirai K, Abe M, Yada T, Ishibashi Y, Fujimura A, Mukai T, Ueno M, Okada T, Yoshikawa M, Kawaguchi J (2011) Irradiation history of Itokawa regolith material deduced from noble gases in the Hayabusa samples. Science 333:1128-1131

19. Welten KC, Caffee MW, Leya I, Masarik J, Nishiizumi K, Wieler R (2003) Noble gases and cosmogenic radionuclides in the Gold Basin L4 chondrite shower: Thermal history, exposure history, and pre-atmospheric size. Meteorit Planet Sci. 38:157-173 
Journal of Radioanalytical and Nuclear Chemistry

\section{Supplementary information}

The manner in which the spherule sample is placed into the pit in the quartz disc is shown

in Figure 1.

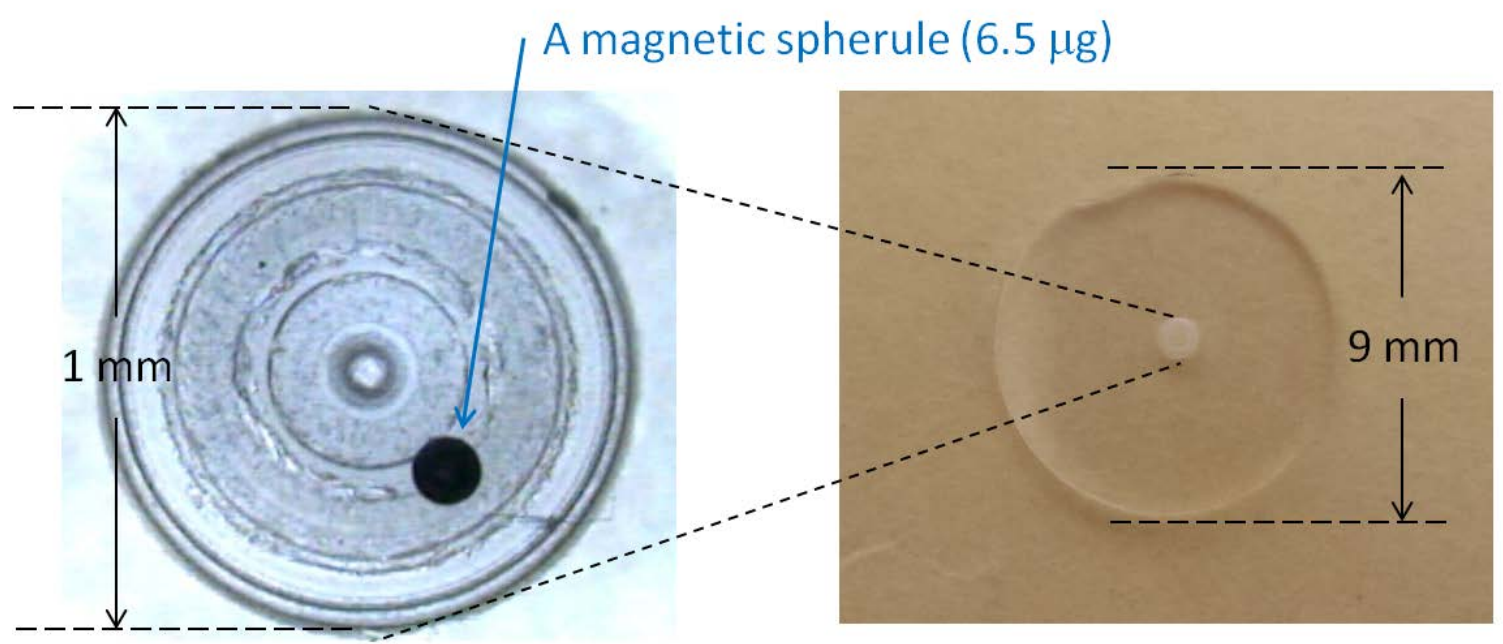

382

A small pit

A quartz disc

384 Nuclear data related to this study are summarized in the following Table 1.

385 Table 1 Data of measured nuclides [S1]

\begin{tabular}{|c|l|c|c|c|c|}
\hline Element & $\begin{array}{l}\text { Nuclear } \\
\text { reaction }\end{array}$ & $\begin{array}{l}\text { Thermal } \\
\text { neutron } \\
\text { cross section } \\
\text { (barn) }\end{array}$ & $\begin{array}{l}\text { Produced } \\
\text { nuclide }\end{array}$ & Half life & $\begin{array}{l}\gamma \text {-ray energy } \\
\text { used for } \\
\text { determination } \\
(\mathrm{keV})\end{array}$ \\
\hline${ }_{11} \mathrm{Na}$ & ${ }^{23} \mathrm{Na}(\mathrm{n}, \gamma)$ & 0.53 & ${ }^{24} \mathrm{Na}$ & $14.96 \mathrm{~h}$ & 1369 \\
\hline $21 \mathrm{Sc}$ & ${ }^{45} \mathrm{Sc}(\mathrm{n}, \gamma)$ & 27 & ${ }^{46} \mathrm{Sc}$ & $83.8 \mathrm{~d}$ & 889 \\
\hline $24 \mathrm{Cr}$ & ${ }^{50} \mathrm{Cr}(\mathrm{n}, \gamma)$ & 15 & ${ }^{51} \mathrm{Cr}$ & $27.7 \mathrm{~d}$ & 320 \\
\hline $26 \mathrm{Fe}$ & ${ }^{58} \mathrm{Fe}(\mathrm{n}, \gamma)$ & 1.3 & ${ }^{59} \mathrm{Fe}$ & $44.5 \mathrm{~d}$ & 1099 \\
\hline${ }_{27} \mathrm{Co}$ & ${ }^{59} \mathrm{Co}(\mathrm{n}, \gamma)$ & 37.2 & ${ }^{60} \mathrm{Co}$ & $5.27 \mathrm{y}$ & 1332 \\
\hline $28 \mathrm{Ni}$ & ${ }^{58} \mathrm{Ni}(\mathrm{n}, \mathrm{p})$ & $0.5^{\mathrm{a}}$ & ${ }^{58} \mathrm{Co}$ & $70.9 \mathrm{~d}$ & 811 \\
\hline${ }_{30} \mathrm{Zn}$ & ${ }^{64} \mathrm{Zn}(\mathrm{n}, \gamma)$ & 0.74 & ${ }^{65} \mathrm{Zn}$ & $244.3 \mathrm{~d}$ & 1115 \\
\hline $57 \mathrm{La}$ & ${ }^{139} \mathrm{La}(\mathrm{n}, \gamma)$ & 9.2 & ${ }^{140} \mathrm{La}$ & $40.272 \mathrm{~h}$ & 1595 \\
\hline${ }_{62} \mathrm{Sm}$ & ${ }^{152} \mathrm{Sm}(\mathrm{n}, \gamma)$ & 206 & ${ }^{153} \mathrm{Sm}$ & $46.27 \mathrm{~h}$ & 103 \\
\hline $77 \mathrm{Ir}$ & ${ }^{191} \mathrm{Ir}(\mathrm{n}, \gamma)$ & 920 & ${ }^{192} \mathrm{Ir}$ & $73.8 \mathrm{~d}$ & 317 \\
\hline
\end{tabular}


Journal of Radioanalytical and Nuclear Chemistry

\begin{tabular}{|c|c|c|c|c|c|}
\hline $79 \mathrm{Au}$ & ${ }^{197} \mathrm{Au}(\mathrm{n}, \gamma)$ & 98.7 & ${ }^{198} \mathrm{Au}$ & $2.69 \mathrm{~d}$ & 411 \\
\hline
\end{tabular}

387 S1. Magill J, Pfennig G, Galy J (2006) Karlsruhe Chart of the Nuclides, $7^{\text {th }}$ Edition.

388 European Commission, Joint Research Centre, Luxembourg

389 S2. Shibata K, Iwamoto O, Nakagawa T, Iwamoto N, Ichihara A, Kunieda S, Chiba S, 390 Furutaka K, Otuka N, Ohsawa T, Murata T, Matsunobu H, Zukeran A, Kamada S, $391 \quad$ Katakura J (2011) JENDL-4.0: A new library for nuclear science and engineering. J

$392 \quad$ Nucl Sci Technol. 48:1-30

393 